\title{
Extracorporeal membrane oxygenation for refractory acute respiratory distress syndrome in severe malaria
}

\author{
Carlos Alves ${ }^{1}$, Jen-Ting Chen ${ }^{2}$, Nina Patel ${ }^{2}$, Darryl Abrams², Paulo Figueiredo ${ }^{1}$, Lurdes Santos ${ }^{1}$, António Sarmento ${ }^{1}$, \\ José Artur Paiva ${ }^{3}$, Matthew Bacchetta ${ }^{2}$, May-Lin Wilgus ${ }^{2}$, Roberto Roncon-Albuquerque $\mathrm{Jr}^{3}$ and Daniel Brodie ${ }^{2^{*}}$
}

\begin{abstract}
Background: Severe malaria may be complicated by the acute respiratory distress syndrome (ARDS), which is associated with a high mortality. In the present report, a series of three cases of imported malaria complicated by refractory severe ARDS supported with extracorporeal membrane oxygenation (ECMO) is presented.

Methods: One female and two male adult patients (ages 39 to 53) were included. Two patients had Plasmodium falciparum infection and one patient had Plasmodium vivax and Plasmodium ovale co-infection. Anti-malarial therapy consisted in intravenous quinine (in two patients) and intravenous quinidine (in one patient), plus clindamycin or doxycycline.

Results: Despite lung protective ventilation, a conservative strategy of fluid management, corticosteroids (two patients), prone position (two patients) and inhaled nitric oxide (one patient), refractory severe ARDS supervened $\left(\mathrm{PaO}_{2}\right.$ to $\mathrm{FiO}_{2}$ ratio 68) and venovenous ECMO was then initiated. In one patient, a bicaval dual-lumen cannula was inserted; in the two other patients, a two-site configuration was used. Two patients survived to hospital-discharge (duration of ECMO support: 8.5 days) and one patient died from nosocomial sepsis and multi-organ failure after 40 days of ECMO support.

Conclusions: ECMO support allowed adequate oxygenation and correction of hypercapnia under lung protective ventilation, therefore reducing ventilator-induced lung injury. ECMO referral should be considered early in malaria complicated by severe ARDS refractory to conventional treatment.
\end{abstract}

Keywords: Extracorporeal membrane oxygenation, Acute respiratory distress syndrome, Malaria, Plasmodium falciparum

\section{Background}

Malaria is responsible for more than one million deaths annually, the majority of which occur in sub-Saharan Africa, with Plasmodium falciparum as the predominant organism [1]. In non-endemic regions, most cases occur in non-immune or semi-immune travellers returning from endemic countries who do not adhere to malaria chemoprophylaxis [2,3]. Such cases may be particularly severe, with in-hospital mortality rates reported as 11 to

\footnotetext{
*Correspondence: hdb5@columbia.edu

${ }^{2}$ Division of Cardiothoracic Surgery, Columbia University College of Physicians and Surgeons, 630 W. 168th St., PH 8 East, New York, NY 10032, USA

Full list of author information is available at the end of the article
}

40\% [2,4-6]. Acute respiratory distress syndrome (ARDS), which may develop in either the acute or late phases of infection, has been reported in 5 to $25 \%$ of adults with severe P. falciparum and in 1 to $10 \%$ of patients with severe Plasmodium vivax [1], with an attributable mortality of $20 \%$ in developed countries [5].

Extracorporeal membrane oxygenation (ECMO), referring to an extracorporeal circuit that directly oxygenates and removes carbon dioxide from the blood, may be considered in patients with ARDS whose pulmonary injury is so severe that positive-pressure ventilation alone is insufficient to maintain adequate gas exchange, or when adherence to lung-protective ventilation strategies results in unacceptable levels of hypercapnia and acidaemia [7]. In

\section{Biomed Central}


most cases of ECMO for severe ARDS, venovenous ECMO is utilized, in which blood is withdrawn from and returned to a central vein. Recently, there has been increasing interest in ECMO as a result of advances in extracorporeal technology, with more efficient oxygenators and lower rates of complications, along with several reports of improved survival with ECMO for severe ARDS [8-11]. However, reports of ECMO for severe ARDS in patients with malaria are uncommon, with only two cases reported separately in the literature [5,12], as well as one case of extracorporeal carbon dioxide elimination [13]. In the present report, a series of three cases of malaria complicated by severe ARDS refractory to conventional treatment and supported with ECMO is presented.

\section{Methods}

\section{Case 1}

A 53-year-old Portuguese man with a history of diabetes and myocardial infarction presented with five days of fever, chills, headache and myalgias (Table 1). The patient had been living in Angola, and he was not taking any malaria prophylaxis. The patient was evaluated at Hospital S João (Porto, Portugal), where vital signs and physical examination were unremarkable. Blood smear revealed P. falciparum ( $2 \%$ parasitaemia) and severe thrombocytopaenia $(17,000$ platelets $/ \mu \mathrm{l})$. The patient was initially admitted in a regular ward and oral quinine sulphate plus doxycycline were administered. However, shortly after admission, he developed vomiting with intolerance to oral drugs. In that context, intravenous quinine and doxycycline were started. No arrhythmia occurred during quinine treatment. The patient developed progressive hypoxemic respiratory failure requiring invasive mechanical ventilation (IMV) on hospital day 3 despite antimicrobials, diuresis, and clearance of his parasitaemia (Table 2). Blood cultures (obtained on hospital and ICU admission), urine culture and pneumococcal and Legionella urinary antigen tests, bacteriologic and virologic exams of tracheal secretions and bronchoalveolar lavage (performed immediately after tracheal intubation) were all negative. His thoracic

Table 1 Characteristics of patients with malaria-related severe ARDS requiring ECMO

\begin{tabular}{|c|c|c|c|}
\hline Patient & 1 & 2 & 3 \\
\hline Age (years) & 53 & 39 & 46 \\
\hline Gender & Male & Male & Female \\
\hline Country of origin & Angola & Mozambique & Uganda \\
\hline Plasmodium species & P. falciparum & P. falciparum & $P$. vivax and $P$. ovale \\
\hline \multicolumn{4}{|l|}{ Clinical deterioration (days) } \\
\hline Symptoms to hospital admission & 5 & 3 & 14 \\
\hline Hospital to ICU admission & 2 & 3 & 4 \\
\hline ICU admission to ECMO & 9 & 14 & 1 \\
\hline IMV to ECMO & 8 & 11 & 1 \\
\hline Murray score & 3.75 & 3.75 & 4.0 \\
\hline \multicolumn{4}{|l|}{ Before ECMO } \\
\hline Prone position & Yes & Yes & No \\
\hline Nitric oxide & No & No & Yes \\
\hline Renal replacement therapy & No & No & No \\
\hline \multicolumn{4}{|l|}{ During ECMO } \\
\hline Prone position & No & No & No \\
\hline Nitric oxide & No & No & No \\
\hline Renal replacement therapy & Yes & No & No \\
\hline APACHE II * & 11 & 14 & 17 \\
\hline Mechanical ventilation (days) & 48 & 25 & 17 \\
\hline ECMO (days) & 40 & 7 & 10 \\
\hline ICU LOS (days) & 49 & 46 & 23 \\
\hline ICU survival & NSurv & Surv & Surv \\
\hline Hospital survival & NSurv & Surv & Surv \\
\hline
\end{tabular}


Table 2 Respiratory and haematologic parameters before, during, and after ECMO

\begin{tabular}{lccc}
\hline Patient & $\mathbf{1}$ & $\mathbf{2}$ & $\mathbf{3}$ \\
\hline ICU admission & & & \\
Ventilation & $\mathrm{SB}$ & $\mathrm{NIV}$ & $\mathrm{IMV}$ \\
$\mathrm{FiO}_{2}(\%)$ & 85 & 50 & 100 \\
$\mathrm{pH} / \mathrm{PaCO}_{2}(\mathrm{mmHg})$ & $7.50 / 36.2$ & $7.41 / 39.4$ & $7.41 / 39$ \\
Haemoglobin $(\mathrm{g} / \mathrm{dL})$ & 11.4 & 12.0 & 9.6 \\
Parasitaemia $(\%)$ & Negative & Negative & 0.015
\end{tabular}

\section{Before ECMO}

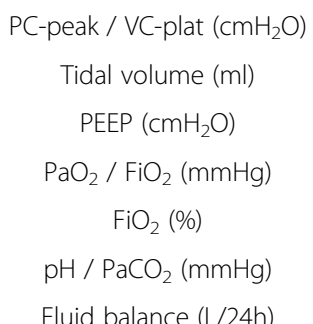

\section{Day 2 on ECMO}

\begin{tabular}{|c|c|c|c|}
\hline PC-peak / VC-plat $\left(\mathrm{cmH}_{2} \mathrm{O}\right)$ & 28 & 26 & 26 \\
\hline Tidal volume (ml) & 280 & 340 & 210 \\
\hline PEEP $\left(\mathrm{cmH}_{2} \mathrm{O}\right)$ & 10 & 10 & 10 \\
\hline $\mathrm{FiO}_{2}(\%)$ & 60 & 55 & 40 \\
\hline ECMO-BF (lpm) & 3.0 & 3.0 & 3.5 \\
\hline ECMO-sweep (Ipm) & 2.0 & 3.0 & 3.0 \\
\hline $\mathrm{pH} / \mathrm{PaCO}_{2}(\mathrm{mmHg})$ & $7.40 / 47.0$ & $7.44 / 54.0$ & $7.45 / 36.0$ \\
\hline Fluid balance (L/24h) & +1.55 & +0.85 & +2.70 \\
\hline \multicolumn{4}{|l|}{ End of ECMO } \\
\hline PC-peak / VC-plat $\left(\mathrm{cmH}_{2} \mathrm{O}\right)$ & 31 & 28 & 23 \\
\hline Tidal volume (ml) & 110 & 560 & 385 \\
\hline PEEP $\left(\mathrm{cmH}_{2} \mathrm{O}\right)$ & 8 & 8 & 12 \\
\hline $\mathrm{FiO}_{2}(\%)$ & 60 & 50 & 50 \\
\hline ECMO-BF (Ipm) & 3.0 & 3.0 & 3.3 \\
\hline ECMO-sweep (lpm) & 7.0 & 2.5 & 1.5 \\
\hline $\mathrm{pH} / \mathrm{PaCO}_{2}(\mathrm{mmHg})$ & $7.22 / 33.0$ & $7.43 / 38.5$ & $7.43 / 42$ \\
\hline Fluid balance (L/24h) & +1.85 & +0.80 & +0.48 \\
\hline \multicolumn{4}{|l|}{ ICU discharge } \\
\hline Ventilation & NA & SB & SB \\
\hline $\mathrm{FiO}_{2}(\%)$ & NA & 27 & 40 \\
\hline $\mathrm{pH} / \mathrm{PaCO}_{2}(\mathrm{mmHg})$ & NA & $7.47 / 30.7$ & $7.44 / 38.0$ \\
\hline
\end{tabular}

ECMO-BF, blood flow through the ECMO circuit; ECMO-Sweep, sweep gas flow through the ECMO circuit; IVM, invasive mechanical ventilation; NA, not applicable; NIV, non-invasive ventilation; $\mathrm{PaCO}_{2}$, arterial carbon dioxide partial pressure; PEEP, positive end-expiratory pressure; $\mathrm{PC}$-peak, peak inspiratory pressure under pressure control ventilation; $\mathrm{SB}$, spontaneous breathing; VC-plat, plateau pressure under volume control ventilation.

CT scan revealed bilateral parenchymal consolidation in gravity-dependent areas and ground-glass-appearing opacities of lung parenchyma, compatible with severe
ARDS (Figure 1A). Echocardiography was performed showing preserved ejection fraction and normal diastolic function. Moreover, plasma BNP was not elevated $(98 \mathrm{pg} / \mathrm{ml})$. Haemodynamic monitoring using the transpulmonary thermodilution technique and arterial pulse contour analysis $\left(\mathrm{PiCCO}^{\circ}\right.$; Philips) was also performed before ECMO treatment, the results being consistent with ARDS (increased (23.7; normal range $3.0-7.0 \mathrm{ml} / \mathrm{kg}$ ) extravascular lung water index (ELWI) and increased (6.6; normal range 1.0-3.0) pulmonary vascular permeability index (PVPI)), without intravascular volume overload (decreased (672; normal range $850-1000 \mathrm{ml} / \mathrm{m}^{2}$ ) intrathoracic blood volume index (ITBI) and decreased (538; normal range $680-800 \mathrm{ml} / \mathrm{m}^{2}$ ) global enddiastolic volume index (GEDI)). Cardiac index (3.6; normal range $3.0-5.0 \mathrm{l} / \mathrm{min} / \mathrm{m}^{2}$ ) and systemic vascular resistance index
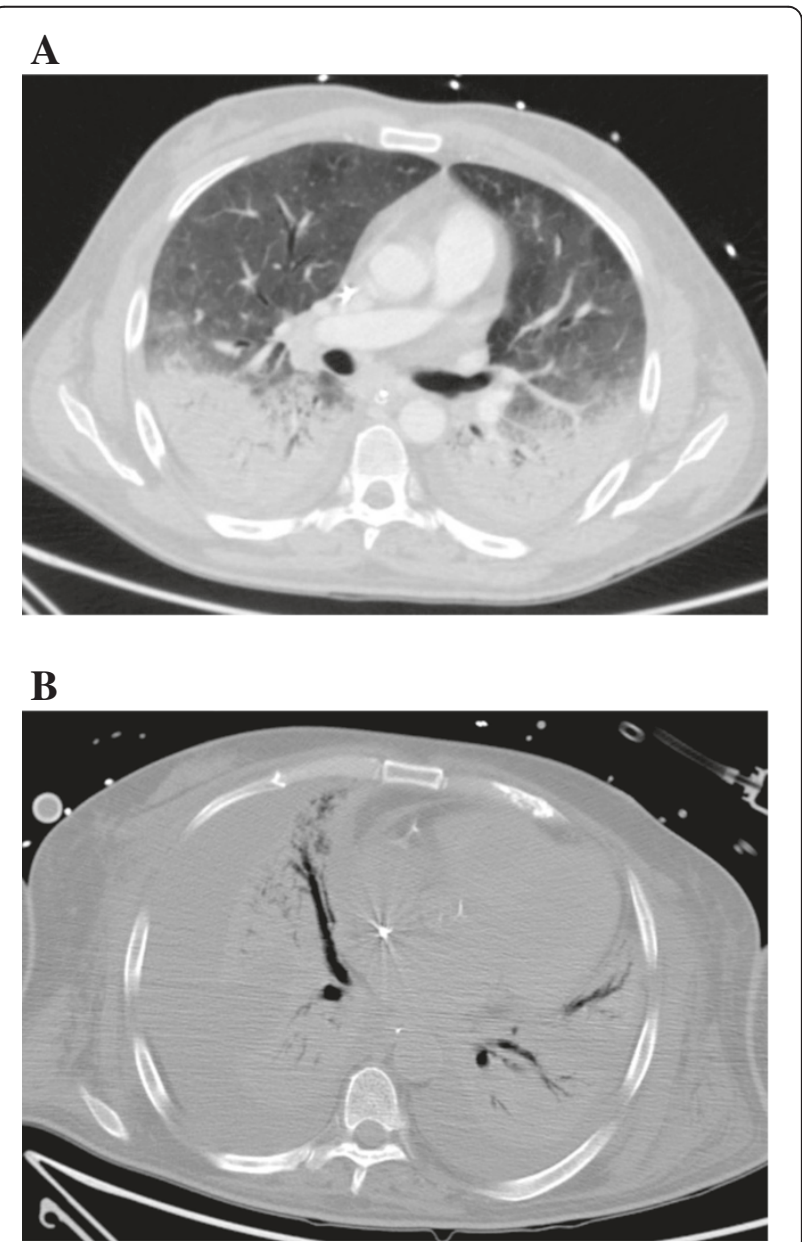

Figure 1 Thoracic computed tomography $(\mathrm{CT})$ before ECMO implantation (A) and after $\mathbf{4 0}$ days of ECMO support (B) in Patient 1. A. Bilateral parenchymal consolidation in gravity-dependent areas and ground-glass-appearing opacities of lung parenchyma, compatible with severe ARDS. B. Extensive parenchymal consolidation and bilateral pleural effusions with associated compression atelectasis after 40 days of W-ECMO. 
(1838; normal range $1700-2400$ dyn ${ }^{*} \mathrm{~s}^{*} \mathrm{~cm}^{-5 *} \mathrm{~m}^{2}$ ) were also recorded. On day 7 of IMV, his $\mathrm{PaO}_{2}$ was $69 \mathrm{mmHg}$ with a $\mathrm{FiO}_{2}$ of 1.0 and PEEP of $13 \mathrm{~cm}$ of water, without improvement with a conservative strategy of fluid management, prone positioning or corticosteroids. ECMO was initiated with placement of a 21Fr right femoral venous drainage cannula and a $15 \mathrm{Fr}$ right internal jugular venous re-infusion cannula. The ventilator was then set to a lung-protective strategy (Table 2). On hospital day 20, ventilator-associated pneumonia occurred and Pseudomonas aeruginosa was isolated in cultures from bronchoalveolar lavage and blood. On hospital day 40 a new episode of VAP occurred and Escherichia coli was isolated in cultures from tracheal aspirate and on hospital day 48 septic shock with multi-organ failure supervened and Pseudomonas aeruginosa was isolated from the blood and tracheal aspirate. The patient died on hospital day 49 (ECMO day 40; Figure 1B). The only ECMO-related complication was thrombus formation in the oxygenator, requiring exchange on ECMO day 29.

\section{Case 2}

A 39-year-old Portuguese man with a history of hypertension and a prior episode of malaria treated as an outpatient, presented with three days of fever, myalgias, headache, nausea and vomiting (Table 1). The patient had worked for several years in Mozambique, and he was not taking any malaria prophylaxis. On presentation, he was febrile and somnolent. Chest X-ray was normal. Blood smear revealed P. falciparum (3\% parasitaemia) and thrombocytopaenia $(80,000$ platelets $/ \mu \mathrm{l})$. Taking into account the presence of vomiting with intolerance to oral drugs, the patient was treated with intravenous quinine and clindamycin. Despite negative cultures and clearance of his parasitaemia, hypoxemic respiratory failure developed on hospital day 6, requiring IMV (Table 2). Blood cultures (obtained on hospital and ICU admission), urine culture and urinary antigens (pneumococcal and Legionella), bacteriologic and virologic examinations of tracheal secretions and bronchoalveolar lavage (performed immediately after tracheal intubation) were all negative. Chest X-ray showed bilateral infiltrates and echocardiogram was unremarkable (Figure 2A). On day 11 of IMV, his $\mathrm{PaO}_{2}$ was $62 \mathrm{mmHg}$ despite an $\mathrm{FIO}_{2}$ of 1.0, PEEP of $12 \mathrm{~cm}$ of water, a conservative strategy of fluid management, prone positioning, and corticosteroids. ECMO was then initiated with a 23Fr drainage cannula in the right femoral vein and 17Fr re-infusion cannula in the right internal jugular vein. The patient was successfully decannulated after seven days of ECMO support and weaned off IMV within the next seven days (Figure 2B). There were no ECMO-related complications. He was discharged home two weeks post-ICU discharge, where he has been living independently.

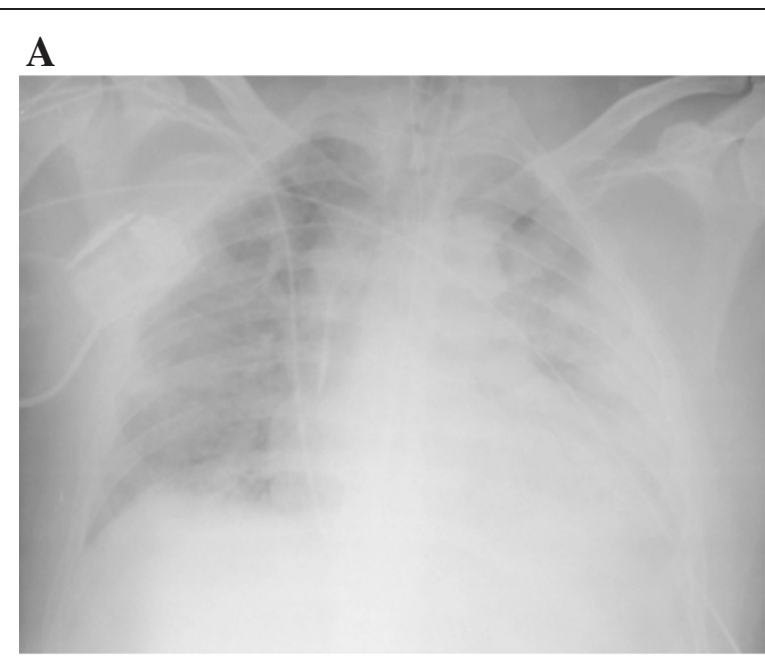

\section{B}

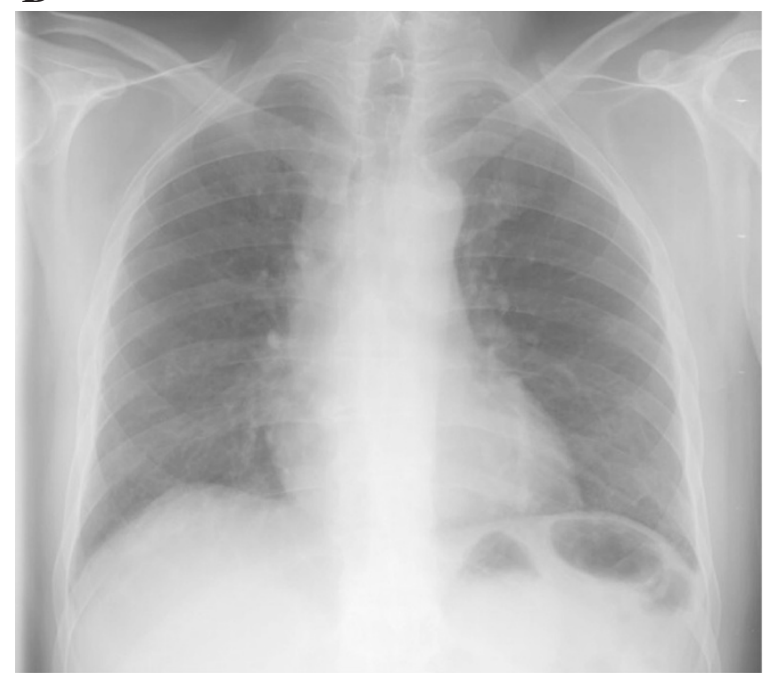

Figure 2 Chest X-ray before ECMO implantation (A) and before hospital discharge (B) in Patient 2. A. Bilateral parenchymal

consolidation with air bronchograms, compatible with severe ARDS. B. Complete resolution of bilateral infiltrates.

\section{Case 3}

A 46-year-old American woman presented with two weeks of cyclic fevers, night sweats, and myalgias (Table 1). She had recently returned from Uganda, where she worked in a rural area and was adherent to atovaquone and proguanil malaria prophylaxis. She was treated empirically for chloroquine-resistant $P$. falciparum with oral quinine and doxycycline, however she did not tolerate oral therapy due to nausea and vomiting, and required admission to a local hospital for initiation of intravenous quinidine and clindamycin. Her vital signs, physical exam, and chest X-ray were unremarkable. Initial blood smears showed $0.5 \%$ parasitaemia. Once PCR testing confirmed $P$. vivax and $P$. ovale and excluded $P$. falciparum, her treatment was changed to chloroquine; however severe 
hypoxemic respiratory failure with bilateral infiltrates developed by hospital day 4, requiring IMV, at which point intravenous therapy was resumed. $\mathrm{PaO}_{2}$ was 68 mmHg despite an $\mathrm{FIO}_{2}$ of 1.0, PEEP of $15 \mathrm{~cm}$ of water, a conservative strategy of fluid management and inhaled nitric oxide (iNO) (Table 2). Echocardiogram demonstrated normal cardiac function. She was transferred to the Columbia University College of Physicians and Surgeons (New York, NY, USA), where she was placed on ECMO with a $27 \mathrm{Fr}$ bicaval dual-lumen cannula via the right internal jugular vein under fluoroscopic and echocardiographic guidance $[14,15]$. Cultures and blood smears in the ICU were negative for organisms. Anti-malarial therapy with intravenous quinidine and doxycycline was continued and she was successfully decannulated on ECMO day 10, and liberated from IMV seven days later. No arrhythmias occurred during quinine treatment. One month post-discharge, she was functioning independently. Two ECMO-related complications occurred: i) migration of the distal end of the cannula into a hepatic vein, identified by transesophageal echocardiogram on ECMO day 2 in the setting of a decrease in blood flow rates, followed by successful repositioning at the bedside; and ii) bleeding from the cannulation site and epistaxis that required a total of 8 units of packed red blood cells in the setting of lowlevel anticoagulation to maintain ECMO circuit integrity (mean activated partial thromboplastin time 46.5 seconds).

\section{Consent}

Informed consent was obtained from the patients for publication of this case series and any accompanying images after explanation of the report objectives.

\section{Discussion}

In this report, three cases of imported malaria complicated by severe ARDS supported with ECMO are presented. Severe ARDS may be a complication of P. falciparum, $P$. vivax or $P$. ovale infections. In accordance with the WHO guidelines the presence of ARDS is a defining criterion for severe malaria [16]. In all three cases, oxygenation and $\mathrm{CO}_{2}$ clearance through the membrane ECMO lung allowed the compliance to protective ventilation of the native lung with low tidal volumes $(<6 \mathrm{ml} / \mathrm{kg} \mathrm{IBW})$ and low-fractional oxygen concentrations, limiting ventilatorinduced lung injury [17]. However, permissive hypercapnia is frequently necessary to allow low tidal volume protective ventilation in severe ARDS. This could be potentially harmful in patients with severe malaria, given that cerebral oedema with elevated intracranial pressures can complicate cerebral malaria [18] and that hypercapnia causes cerebral vasodilatation and intracranial pressure elevation. Moreover, microvascular congestion and sequestration of parasitized red blood cells was shown to be a common feature in cerebral malaria, leading to impaired tissue perfusion that may cause diffuse cerebral ischemia and increased intracranial blood volume [19]. The use of ECMO in patients with severe malaria, allowing strict control of patient's $\mathrm{PaCO} 2$, potentially limits intracranial pressure elevation.

Fluid management is crucial in patients with severe malaria. Taking into account that in these patients pulmonary edema secondary to increased pulmonary vascular permeability has been shown to be frequent, unpredictable and exacerbated by fluid loading, a conservative strategy of fluid management was followed in all three patients before and after ECMO initiation [20]. Moreover, a liberal strategy of fluid management in acute lung injury has been previously associated with prolonged duration of mechanical ventilation and intensive care [21].

ECMO is not without risks and there are no definitive criteria for ECMO treatment in adult ARDS. Therefore, ECMO should only be considered in adult patients with malaria and severe ARDS refractory to conventional treatment. The recently conducted CESAR trial showed favourable results of ECMO referral for adult patients with severe ARDS [8]. In that context, the same inclusion (Murray score $>3.0$ or $\mathrm{pH}<7.20$ ) and exclusion (high pressure ( $>30 \mathrm{~cm} \mathrm{H}_{2} \mathrm{O}$ of peak inspiratory pressure) or high $\mathrm{FiO}_{2}(>0.8)$ ventilation for more than seven days; intracranial bleeding; any other contraindication to limited heparinization) criteria for ECMO consideration in malaria and severe ARDS were used in the present case series.

Severe imported malaria is an important problem in the western world due to the increasing number of travellers returning from endemic countries who are non-adherent to malaria chemoprophylaxis [22]. Most imported cases occur in non-immune patients in whom malaria can rapidly progress to severe disease, with mortality as high as 20 to $35 \%$, even with adequate anti-malarial treatment [23]. ARDS may develop in isolation or as part of a severe multisystem illness and often occurs within a few days of starting treatment when parasitaemia is falling [24]. The pathogenesis of ARDS in malaria is not fully understood, though it may involve parasite sequestration in the pulmonary vasculature and up-regulation of pro-inflammatory cytokines, and may persist even after parasite clearance [1]. However, parasite sequestration in the pulmonary vasculature seems to be relevant only for $P$. falciparum infection, given that in $P$. vivax malaria there is no substantial lung sequestration. Severe ARDS in patients with malaria has a poor prognosis, with mortality as high as 69 to $95 \%$ in observational ICU case series [22,25]. Severe ARDS most commonly complicates $P$. falciparum infection and is rarely a complication of $P$. vivax or $P$. ovale infection. This could be related to differences in cyto-adhesion of infected erythrocytes [26-29]. However, it should be stressed that it is difficult to definitely establish malaria as the sole etiology for severe ARDS, fully excluding bacterial co-infection. Nevertheless, no documentation of bacterial co-infection 
was found despite extensive microbiology specimen collection and culture at ICU admission. This could support the assumption that malaria was the most probable cause for severe ARDS in the three cases presented in this report.

Risk factors associated with the development of ARDS in malaria include advanced age, lack of specific immunity, immunocompromised status, and pregnancy. A high parasitic burden is not necessary [30]. In this case series, patients were either semi-immune or non-immune and parasitaemia was less than $4 \%$ in all patients.

There are only two prior cases reported separately on the use of ECMO for severe ARDS in patients with malaria, as well as one case on the use of extracorporeal carbon dioxide elimination $[5,12,13]$. In both cases of ECMO use, $P$. falciparum was identified as the causal organism and ECMO was instituted within seven days for refractory hypoxaemia, but only one patient survived $[5,12]$. In the case of extracorporeal carbon elimination use, $P$. falciparum was also identified as the causal organism and extracorporeal carbon elimination was instituted on the $17^{\text {th }}$ day, being discontinued after twelve days. The patient was weaned from mechanical ventilation and successfully discharged home [13]. In the present case series, one of the two patients that initiated ECMO after more than seven days of IMV did not survive. Patients with ARDS who have been receiving IMV with excessively high plateau pressures or high fractions of inspired oxygen for more than seven days may be less likely to benefit from ECMO [31-35]. Earlier initiation of ECMO, for these or other reasons, has been associated with better outcomes in some, but not all, observational studies [33,36-38].

Patients with severe forms of malaria are highly susceptible to bacterial infections and concomitant antibacterial therapy is recommended [2,39]. All the three patients presented in this case series received adequate antimicrobial therapy, though one patient developed nosocomial infections and ultimately died of sepsis, despite appropriate antibacterial coverage.

ECMO-related complications in the present case series included cannula migration into a hepatic vein, which was identified by transesophageal echocardiogram and corrected at the bedside. Thrombus formation in the oxygenator was ultimately the cause for oxygenator exchange in one patient. However, the rate of thrombosisassociated oxygenator failure requiring device exchange is low, even at low levels of anticoagulation [14]. Major bleeding complications, as occurred in one patient, are less frequent in the era of modern ECMO technology, given the ability to maintain circuit integrity at lower levels of anticoagulation, but they may still occur, especially in the setting of pre-existing thrombocytopaenia or coagulopathy.

In conclusion, severe ARDS can complicate $P$. falciparum, $P$. vivax, and $P$. ovale infection. In regions where the technology is available, ECMO referral should be considered for patients with malaria complicated by severe ARDS refractory to conventional treatment. Taking into account the limited experience with ECMO in severe malaria yet, its use should be performed in experienced ECMO centers. In fact, severe malaria can cause haemolysis, disseminated intravascular coagulation and low platelets, which might be exaggerated by the use of extracorporeal devices.

\section{Competing interests}

The authors declare that they have no competing interests.

\section{Authors' contributions}

CA, JTC, NP, DA, RRA and DB wrote the paper. CA, PF, LS, AS, JAP and RRA were the physicians responsible for Patient 1 and Patient 2. JTC, NP, DA, MB, MLW and DB were the physicians responsible for Patient 3. RRA and DB conceived the study, its design and coordination. All authors have read and approved the final manuscript.

\section{Author details}

${ }^{1}$ Department of Infectious Diseases, Centro Hospitalar S. João, Porto, Portugal. ${ }^{2}$ Division of Cardiothoracic Surgery, Columbia University College of Physicians and Surgeons, 630 W. 168th St., PH 8 East, New York, NY 10032 USA. ${ }^{3}$ Department of Intensive Care Medicine, Centro Hospitalar S.João, Porto, Portugal.

Received: 4 July 2013 Accepted: 29 August 2013

Published: 31 August 2013

\section{References}

1. Taylor WR, Hanson J, Turner GD, White NJ, Dondorp AM: Respiratory manifestations of malaria. Chest 2012, 142:492-505.

2. Santos LC, Abreu CF, Xerinda SM, Tavares M, Lucas R, Sarmento AC: Severe imported malaria in an intensive care unit: a review of 59 cases. Malar J 2012, 11:96.

3. Frickmann H, Schwarz NG, Holtherm HU, Maassen W, Vorderwulbecke F, Erkens K, Fischer M, Morwinsky T, Hagen RM: Compliance with antimalarial chemoprophylaxis in German soldiers: a 6-year survey. Infection 2013, 41:311-320.

4. Bruneel F, Hocqueloux L, Alberti C, Wolff M, Chevret S, Bedos JP, Durand R, Le Bras J, Regnier B, Vachon F: The clinical spectrum of severe imported falciparum malaria in the intensive care unit: report of 188 cases in adults. Am J Respir Crit Care Med 2003, 167:684-689.

5. Losert H, Schmid K, Wilfing A, Winkler S, Staudinger T, Kletzmayr J, Burgmann $\mathrm{H}$ : Experiences with severe $P$. falciparum malaria in the intensive care unit. Intensive Care Med 2000, 26:195-201.

6. De Nardo P, Oliva A, Giancola ML, Ghirga P, Mencarini P, Bibas M, Nicastri E, Antinori A, Corpolongo A: Haemolytic anaemia after oral artemetherlumefantrine treatment in a patient affected by severe imported falciparum malaria. Infection 2013, 41:863-865. Epub ahead of print.

7. Brodie D, Bacchetta M: Extracorporeal membrane oxygenation for ARDS in adults. N Engl J Med 2011, 365:1905-1914.

8. Peek GJ, Mugford M, Tiruvoipati R, Wilson A, Allen E, Thalanany MM, Hibbert CL, Truesdale A, Clemens F, Cooper N, Firmin RK, Elbourne D: CESAR trial collaboration: efficacy and economic assessment of conventional ventilatory support versus extracorporeal membrane oxygenation for severe adult respiratory failure (CESAR): a multicentre randomised controlled trial. Lancet 2009, 374:1351-1363.

9. Davies A, Jones D, Bailey M, Beca J, Bellomo R, Blackwell N, Forrest P, Gattas D, Granger E, Herkes R, Jackson A, McGuinness S, Nair P, Pellegrino V, Pettilä V, Plunkett B, Pye R, Torzillo P, Webb S, Wilson M, Ziegenfuss M, Australia and New Zealand Extracorporeal Membrane Oxygenation (ANZ ECMO) Influenza Investigators: Extracorporeal membrane oxygenation for 2009 Influenza A (H1N1) acute respiratory distress syndrome. JAMA 2009, 302:1888-1895.

10. Patroniti N, Zangrillo A, Pappalardo F, Peris A, Cianchi G, Braschi A, lotti GA, Arcadipane A, Panarello G, Ranieri VM, Terragni P, Antonelli M, Gattinoni L, Oleari F, Pesenti A: The Italian ECMO network experience during the 2009 influenza $\mathrm{A}(\mathrm{H} 1 \mathrm{~N} 1)$ pandemic: preparation for severe respiratory emergency outbreaks. Intensive Care Med 2011, 37:1447-1457. 
11. Noah MA, Peek GJ, Finney SJ, Griffiths MJ, Harrison DA, Grieve R, Sadique MZ, Sekhon JS, McAuley DF, Firmin RK, Harvey C, Cordingley JJ, Price S, Vuylsteke A, Jenkins DP, Noble DW, Bloomfield R, Walsh TS, Perkins GD, Menon D, Taylor BL, Rowan KM: Referral to an extracorporeal membrane oxygenation center and mortality among patients with severe 2009 influenza A(H1N1). JAMA 2011, 306:1659-1668.

12. Vandroux D, Leaute B, Hoarau N, Ursulet L, Djouhri S, Braunberger E, Gauzere $B A$ : High frequency oscillation ventilation and extracorporeal membrane oxygenation during pernicious malaria. Med Mal Infect 2011, 41:209-212.

13. Neurath M, Benzing A, Knolle P, Grundmann H, Dippold W, Meyer zum Buschenfelde $\mathrm{KH}$ : Acute respiratory failure in tropical malaria during pregnancy. Successful treatment using extracorporeal CO2 elimination. Dtsch Med Wochenschr 1993, 118:1060-1066.

14. Javidfar J, Brodie D, Wang D, Ibrahimiye AN, Yang J, Zwischenberger JB, Sonett J, Bacchetta M: Use of bicaval dual-lumen catheter for adult venovenous extracorporeal membrane oxygenation. Ann Thorac Surg 2011, 91:1763-1768. discussion 1769.

15. Javidfar J, Wang D, Zwischenberger JB, Costa J, Mongero L, Sonett J, Bacchetta M: Insertion of bicaval dual lumen extracorporeal membrane oxygenation catheter with image guidance. ASAIO J 2011, 57:203-205.

16. WHO: Guidelines for the treatment of malaria. Geneva: WHO; 2010. http:// whqlibdoc.who.int/publications/2010/9789241547925_eng.pdf.

17. Ventilation with lower tidal volumes as compared with traditional tidal volumes for acute lung injury and the acute respiratory distress syndrome: the acute respiratory distress syndrome network. N Engl J Med 2000, 342:1301-1308.

18. White NJ: Lumbar puncture in cerebral malaria. Lancet 1991, 338:640-641.

19. Ponsford MJ, Medana IM, Prapansilp P, Hien TT, Lee SJ, Dondorp AM, Esiri MM, Day NP, White NJ, Turner GD: Sequestration and microvascular congestion are associated with coma in human cerebral malaria. J Infect Dis 2012, 205:663-671.

20. Hanson JP, Lam SW, Mohanty S, Alam S, Pattnaik R, Mahanta KC, Hasan MU, Charunwatthana P, Mishra SK, Day NP, White NJ, Dondorp AM: Fluid resuscitation of adults with severe falciparum malaria: effects on acid-base status, renal function, and extravascular lung water. Crit Care Med 2013, 41:972-981.

21. Wiedemann HP, Wheeler AP, Bernard GR, Thompson BT, Hayden D, de Boisblanc B, Connors AF Jr, Hite RD, Harabin AL: Comparison of two fluid-management strategies in acute lung injury. N Engl J Med 2006, 354:2564-2575.

22. Bruneel F, Tubach F, Corne P, Megarbane B, Mira JP, Peytel E, Camus C, Schortgen F, Azoulay E, Cohen Y, Georges H, Meybeck A, Hyvernat H, Trouillet $J$, Frenoy E, Nicolet L, Roy C, Durand R, Le Bras J, Wolff M: Severe Imported Malaria in Adults (SIMA) Study Group: severe imported falciparum malaria: a cohort study in 400 critically ill adults. PLoS One 2010, 5:e13236.

23. Blumberg L, Lee RP, Lipman J, Beards S: Predictors of mortality in severe malaria: a two year experience in a non-endemic area. Anaesth Intensive Care 1996, 24:217-223

24. Maguire GP, Handojo T, Pain MC, Kenangalem E, Price RN, Tjitra E, Anstey NM: Lung injury in uncomplicated and severe falciparum malaria: a longitudinal study in papua, Indonesia. J Infect Dis 2005, 192:1966-1974.

25. Krishnan A, Karnad DR: Severe falciparum malaria: an important cause of multiple organ failure in Indian intensive care unit patients. Crit Care Med 2003, 31:2278-2284

26. Price RN, Tjitra E, Guerra CA, Yeung S, White NJ, Anstey NM: Vivax malaria: neglected and not benign. Am J Trop Med Hyg 2007, 77:79-87.

27. Rojo-Marcos G, Cuadros-Gonzalez J, Mesa-Latorre JM, Culebras-Lopez AM, de Pablo-Sanchez R: Acute respiratory distress syndrome in a case of Plasmodium ovale malaria. Am J Trop Med Hyg 2008, 79:391-393.

28. Lee EY, Maguire $\mathrm{JH}$ : Acute pulmonary edema complicating ovale malaria. Clin Infect Dis 1999, 29:697-698.

29. Anstey NM, Handojo T, Pain MC, Kenangalem E, Tjitra E, Price RN, Maguire GP: Lung injury in vivax malaria: pathophysiological evidence for pulmonary vascular sequestration and posttreatment alveolar-capillary inflammation. J Infect Dis 2007, 195:589-596.

30. Jindal SK, Aggarwal AN, Gupta D: Adult respiratory distress syndrome in the tropics. Clin Chest Med 2002, 23:445-455.

31. Rouby JJ, Brochard L: Tidal recruitment and overinflation in acute respiratory distress syndrome: yin and yang. Am J Respir Crit Care Med 2007, 175:104-106.

32. Pugin J, Verghese G, Widmer MC, Matthay MA: The alveolar space is the site of intense inflammatory and profibrotic reactions in the early phase of acute respiratory distress syndrome. Crit Care Med 1999, 27:304-312.
33. Pranikoff T, Hirschl RB, Steimle CN, Anderson HL 3rd, Bartlett RH: Mortality is directly related to the duration of mechanical ventilation before the initiation of extracorporeal life support for severe respiratory failure. Crit Care Med 1997, 25:28-32

34. Jackson RM: Pulmonary oxygen toxicity. Chest 1985, 88:900-905.

35. Davis WB, Rennard SI, Bitterman PB, Crystal RG: Pulmonary oxygen toxicity. Early reversible changes in human alveolar structures induced by hyperoxia. N Engl J Med 1983, 309:878-883.

36. Beiderlinden M, Eikermann M, Boes T, Breitfeld C, Peters J: Treatment of severe acute respiratory distress syndrome: role of extracorporeal gas exchange. Intensive Care Med 2006, 32:1627-1631.

37. Mols G, Loop T, Geiger K, Farthmann E, Benzing A: Extracorporeal membrane oxygenation: a ten-year experience. Am J Surg 2000, 180:144-154.

38. Lewandowski K, Rossaint R, Pappert D, Gerlach H, Slama K, Weidemann H, Frey DJ, Hoffmann O, Keske U, Falke KJ: High survival rate in 122 ARDS patients managed according to a clinical algorithm including extracorporeal membrane oxygenation. Intensive Care Med 1997, 23:819-835.

39. Abreu C, Santos L, Poinhos R, Sarmento A: Acute acalculous cholecystitis in malaria: a review of seven cases from an adult cohort. Infection 2013, 41:821-826. Epub ahead of print.

doi:10.1186/1475-2875-12-306

Cite this article as: Alves et al:: Extracorporeal membrane oxygenation for refractory acute respiratory distress syndrome in severe malaria. Malaria Journal 2013 12:306.

\section{Submit your next manuscript to BioMed Central and take full advantage of:}

- Convenient online submission

- Thorough peer review

- No space constraints or color figure charges

- Immediate publication on acceptance

- Inclusion in PubMed, CAS, Scopus and Google Scholar

- Research which is freely available for redistribution

Submit your manuscript at www.biomedcentral.com/submit
C) Biomed Central 